\title{
Factors associated with corneal high-order aberrations before and after femtosecond laser-assisted in situ keratomileusis
}

\author{
Jun Zeng ${ }^{1,2} \wedge$, Gongpu $\operatorname{Lan}^{3}$, Min Zhu ${ }^{1}$, Kai Sun ${ }^{1}$, Qun Shi ${ }^{4}$, Guoqing Ma ${ }^{4}$, Quan Liu ${ }^{2}$ \\ ${ }^{1}$ Department of Ophthalmology, The First People's Hospital of Foshan, Foshan, China; ${ }^{2}$ State Key Laboratory of Ophthalmology, Zhongshan \\ Ophthalmic Centre, Sun Yat-sen University, Guangzhou, China; ${ }^{3}$ School of Physics and Optoelectronic Engineering, Foshan University, Foshan, \\ China; ${ }^{4}$ School of Automation, Foshan University, Foshan, China \\ Contributions: (I) Conception and design: J Zeng; (II) Administrative support: M Zhu, Q Liu; (III) Provision of study materials or patients: J Zeng, M \\ Zhu, Q Liu; (IV) Collection and assembly of data: G Lan, K Sun, Q Shi, G Ma; (V) Data analysis and interpretation: G Lan, K Sun, Q Shi, G Ma; (VI) \\ Manuscript writing: All authors; (VII) Final approval of manuscript: All authors. \\ Correspondence to: Quan Liu. State Key Laboratory of Ophthalmology, Zhongshan Ophthalmic Centre, Sun Yat-sen University, 54 Xianlie South \\ Road, Guangzhou, China. Email: drliuquan@163.com.
}

Background: Corneal high-order aberrations (HOAs) are related to visual quality. However, the factors associated with corneal HOAs before and after femtosecond laser-assisted in situ keratomileusis (FS-LASIK) have not yet been elucidated. The aim of this study is to observe the factors related to corneal HOAs before and after FS-LASIK.

Methods: Prospective observational study was designed to measure corneal HOAs in 149 eyes of 75 patients before and 6 months after FS-LASIK. The relationship between spherical diopter and corneal parameters, including K1 and K2 (horizontal and vertical refractive power of the cornea, respectively), the aspheric characteristics of the cornea $(\mathrm{Q})$, mean radius of the curvature of the cornea $(\mathrm{Rm})$, and central corneal thickness (CCT), with corneal HOAs were analyzed.

Results: The spherical diopter was correlated with trefoil at $30^{\circ}$ before surgery and with vertical coma, four-order astigmatism at $0^{\circ}$, trefoil at $30^{\circ}$, spherical aberration, and six-order spherical aberration after surgery $(\mathrm{P}<0.05)$. CCT was correlated with vertical coma, four-order astigmatism at $0^{\circ}$, trefoil at $30^{\circ}$, and sixorder spherical aberration after surgery $(\mathrm{P}<0.05)$. K1 was correlated with spherical aberration and six-order astigmatism at $0^{\circ}$ before surgery $(\mathrm{P}<0.05)$. K2 was correlated with spherical aberration, six-order astigmatism at $45^{\circ}$, astigmatism at $0^{\circ}$, six-order astigmatism at $0^{\circ}$ before surgery, and trefoil at $30^{\circ}$ after surgery $(\mathrm{P}<0.05)$. $\mathrm{Q}$ was correlated with spherical aberration, six-order spherical aberration, and six-order astigmatism at $45^{\circ}$ $(\mathrm{P}<0.05)$. Rm was correlated with six-order astigmatism at $0^{\circ}$, spherical aberration, six-order astigmatism at $45^{\circ}$ before surgery, and astigmatism at $0^{\circ}$ after surgery $(\mathrm{P}<0.05)$

Conclusions: Corneal parameters and spherical diopter are related to the HOAs of the cornea before and after FS-LASIK.

Keywords: Corneal high-order aberrations (HOAs); femtosecond laser-assisted in situ keratomileusis (FS-LASIK); spherical diopter; corneal parameters; visual quality

Submitted Apr 22, 2021. Accepted for publication May 26, 2021.

doi: $10.21037 /$ atm-21-2367

View this article at: http://dx.doi.org/10.21037/atm-21-2367

\footnotetext{
^ ORCID: 0000-0002-8916-4006.
} 


\section{Introduction}

Femtosecond laser-assisted in situ keratomileusis (FSLASIK) is a type of refractive surgery for the correction of myopia, hyperopia, and astigmatism, and is a safe, effective, and predictable treatment that is widely used to reshape the cornea (1-3). In the current era of corneal refractive surgeries, patients' expectations of quantitative improvement of vision gave increased and "quality of vision" has become an important issue. Significant visual disturbances, such as double vision, halos, starbursts, glare, and a decrease in contrast sensitivity, are often reported by patients and in fact are the most notable complaints after laser refractive surgeries $(4,5)$. Aberration is the difference between a real image and an ideal image, and occurs when the plane wavefront is refracted by Snell's law. Parallel light ideally focuses on only one point, but the eye is often not a perfect circle for focusing incoming light on one point, and an aberration eventually occurs. If an aberration occurs, the quality of vision becomes poorer, and thus, its importance is now being emphasized as a measurement of visual quality.

The cause of degraded visual quality is considered to be primarily high-order aberrations (HOA) induced when the magnitudes of low-order sphero-cylindrical aberrations are reduced during surgery (6). Increased HOAs after laser refractive surgery causes complications that degrade visual quality (7-11). However, complete knowledge of the sources of HOAs is far from established. Basic data regarding the distribution of HOAs of the human eye in normal myopic and post-FS-LASIK surgery populations are essential to gain a better understanding of HOAs and fully characterize optical function. As a dominant structure in determining the refractive power of the eye, the cornea was found to be a critical contributor to wavefront aberrations in the whole eye (12-14). Changes in corneal aberration after FS-LASIK surgery may have a significant effect on visual quality (15). Corneal high-order optical aberration has been found to be linked to contrast visual acuity, image quality, night myopia, and photic complaints (16). With the development of corneal refractive surgery, understanding the human corneal topography and investigating the factors influencing corneal HOAs before and after FS-LASIK is crucial for improving visual quality.

Pentacam (Oculus Optikgeräte GmbH, Wetzlar, Germany) is a rotating Scheimpflug camera that measures Scheimpflug images of the anterior eye segment and provides sharp and crisp images that include information from the anterior corneal surface to the posterior crystalline lens capsule. In our study, Pentacam was used to analyze the parameters and the HOAs of the cornea. K1 and K2 represent the horizontal and vertical refractive power of the cornea, respectively. The aspheric characteristics of the cornea $(\mathrm{Q})$, central corneal thickness (CCT), and mean radius of the curvature of the cornea $(\mathrm{Rm})$ are related to the shape of the cornea. The spherical diopter is related to the intraoperative cutting depth of the cornea. All of these parameters are characteristics of the cornea and may be related to corneal HOAs. However, up to now, no studies have reported the relationship between corneal parameters and spherical diopter with corneal HOAs before and after FS-LASIK. At present, there is no effective method to prevent postoperative high order corneal aberrations. Therefore, we explored the factors related to postoperative corneal high-order aberrations and expected to reduce or even prevent corneal high order aberrations after surgery. This study aimed to measure corneal HOAs before and after FS-LASIK, and clarify the factors influencing corneal HOAs using the rotating Scheimpflug tomography system.

We present the following article in accordance with the STROBE reporting checklist (available at http://dx.doi. org/10.21037/atm-21-2367).

\section{Methods}

\section{Patient population}

In this study, 149 eyes from 75 patients with myopia and myopic astigmatism were randomly enrolled for analysis. The exclusion criteria were as follows: ocular disease (except myopia and myopic astigmatism), previous ocular surgery, and any systemic condition or medication that could have affected the study. All patients were admitted for the correction of myopia and astigmatism using FSLASIK refractive surgery. The surgery was performed in the First People's Hospital of Foshan between July 2018 and April 2020. The research protocol was approved by the Institutional Review Board of the First People's Hospital of Foshan (No. L-2018-3) and adhered to the tenets of the Declaration of Helsinki (as revised in 2013). The study was commenced after obtaining approval from the Ethics Committee of the hospital, and signed informed consent was obtained from all participants.

FS-LASIK surgery preoperative ophthalmic examinations were performed to exclude participants with systemic disease, ocular diseases (other than refractive errors), abnormal corneal topographies, or thin corneas 
$(\leq 450 \mu \mathrm{m})$. These ocular examinations included the bestcorrected visual acuity, subjective and objective refraction, corneal topography and high-order aberrations (HOAs), slit-lamp examination, fundus examination, and intraocular pressure measurement. Levofloxacin eye drops were used 3 days before the surgery. In FS-LASIK, an 8.5 -mm corneal flap was cut at $100-\mu \mathrm{m}$ depth by an IntraLase FS 60 -fs laser (IntraLase, Irvine, CA, USA), and the stroma was removed using an EX500 excimer laser (Alcon, USA) guided by the Custom-Q algorithm. The optical region was $6.5 \mathrm{~mm}$, and the residual corneal stroma thickness was no less than $300 \mu \mathrm{m}$. The flap was carefully repositioned after laser treatment. Patients were required to wear bandage contact lenses (Bausch, NY, USA) to avoid corneal flap displacement and to promote epithelial repair. The contact lenses were removed after 1 day, and the postoperative medication was initiated (tobramycin dexamethasone eye drops, four times daily for 1 week; levofloxacin eye drops, four times daily for $1-2$ weeks; sodium hyaluronate eye drops, four times daily for 2-3 months).

\section{Measurement of corneal parameters and $\mathrm{HOAs}$}

The aberrations of the whole cornea and corneal parameters, such as K1, K2, Rm, Q, and CCT, were measured using Pentacam. This equipment includes a rotating camera that takes 50 images in 2 seconds, and each image contains 500 true elevation points. The internal software can automatically transform the data points into corneal wavefront data using Zernike polynomials. Each patient was measured both preoperatively and at 6 months postoperatively. The images measured with the Scheimpflug device were only used if the data quality statement was defined as OK. We analyzed the corneal HOAs before and after surgery, which included astigmatism at $0^{\circ}$ and $45^{\circ}$, vertical and horizontal coma, trefoil at $0^{\circ}$ and $30^{\circ}$, spherical aberration, four-order astigmatism at $0^{\circ}$ and $45^{\circ}$, five-order vertical and horizontal coma, six-order spherical aberration, and six-order astigmatism at $0^{\circ}$ and $45^{\circ}$.

\section{Statistical analysis}

The SPSS statistical package (IBM Corp., Armonk, NY, USA) was used for analysis. The preoperative and postoperative corneal aberrations were described in Zernike terms and were compared with the preoperative parameters (i.e., spherical diopter, K1, K2, Rm, Q, and CCT). Linear regressions were performed to analyze the correlation between each term of corneal aberrations with the parameters. $\mathrm{P}<0.05$ considered statistically significant, and only results with $\mathrm{P}<0.05$ were presented in the analysis.

\section{Results}

\section{Factors associated with corneal HOAs before FS-LASIK}

All 75 patients completed preoperative and postoperative examinations and were followed up for 6 months. No patients were lost to follow-up. The average age of study participants was $28 \pm 6$ years, and the preoperative spherical diopters ranged from -1.25 to -10.5 diopters. The spherical diopter was negatively correlated with trefoil at $30^{\circ}(\mathrm{r}=-0.32$, $\mathrm{P}<0.01$; Figure 1). CCT was independent of corneal HOAs (Figure 2). K1 was positively correlated with spherical aberration ( $\mathrm{r}=0.32, \mathrm{P}<0.01$; Figure 3$)$, and negatively correlated with six-order astigmatism at $0^{\circ}(\mathrm{r}=-0.18$, $\mathrm{P}<0.05$; Figure 3). K2 was positively correlated with spherical aberration $(\mathrm{r}=0.30, \mathrm{P}<0.01$; Figure 3$)$ and six-order astigmatism at $45^{\circ}(\mathrm{r}=0.19, \mathrm{P}<0.05$; Figure 4$)$, and negatively correlated with astigmatism at $0^{\circ}(\mathrm{r}=-0.31, \mathrm{P}<0.01$; Figure 4$)$ and six-order astigmatism at $0^{\circ}(\mathrm{r}=-0.17, \mathrm{P}<0.05$; Figure 4$)$. $\mathrm{Q}$ was positively correlated with spherical aberration $(\mathrm{r}=0.39, \mathrm{P}<0.01$; Figure 5$)$ and six-order spherical aberration $(\mathrm{r}=0.25, \mathrm{P}<0.05$; Figure 5$)$, and negatively correlated with six-order astigmatism at $45^{\circ}(\mathrm{r}=-0.17, \mathrm{P}<0.05$; Figure 5). $\mathrm{Rm}$ was positively correlated with six-order astigmatism at $0^{\circ}(\mathrm{r}=0.18, \mathrm{P}<0.05$; Figure 6$)$, and negatively correlated with spherical aberration $(\mathrm{r}=-0.31, \mathrm{P}<0.01$; Figure 6$)$ and six-order astigmatism at $45^{\circ}(\mathrm{r}=-0.16, \mathrm{P}<0.05$; Figure 6). $\mathrm{K} 1, \mathrm{~K} 2$, and Q were positively correlated with spherical aberration, whereas $\mathrm{Rm}$ was negatively correlated with spherical aberration.

\section{Factors associated with corneal HOAs after FS-LASIK}

The spherical diopter was positively correlated with vertical coma $(\mathrm{r}=0.21, \mathrm{P}<0.05$; Figure 1$)$ and four-order astigmatism at $0^{\circ}(\mathrm{r}=0.34, \mathrm{P}<0.01$; Figure 1$)$, and negatively correlated with trefoil at $30^{\circ}(\mathrm{r}=-0.22, \mathrm{P}<0.05$; Figure 1$)$, spherical aberration $(\mathrm{r}=-0.38, \mathrm{P}<0.01$; Figure 1$)$, and sixorder spherical aberration $(\mathrm{r}=-0.66, \mathrm{P}<0.01$; Figure 1$)$. CCT was positively correlated with vertical coma $(\mathrm{r}=0.21$, $\mathrm{P}<0.05$; Figure 2) and four-order astigmatism at $0^{\circ}$ $(\mathrm{r}=0.23, \mathrm{P}<0.05$; Figure 2$)$, and negatively correlated with trefoil at $30^{\circ}(\mathrm{r}=-0.22, \mathrm{P}<0.05$; Figure 2$)$ and six-order spherical aberration $(\mathrm{r}=-0.35, \mathrm{P}<0.01$; Figure 2$) . \mathrm{K} 1$ and 

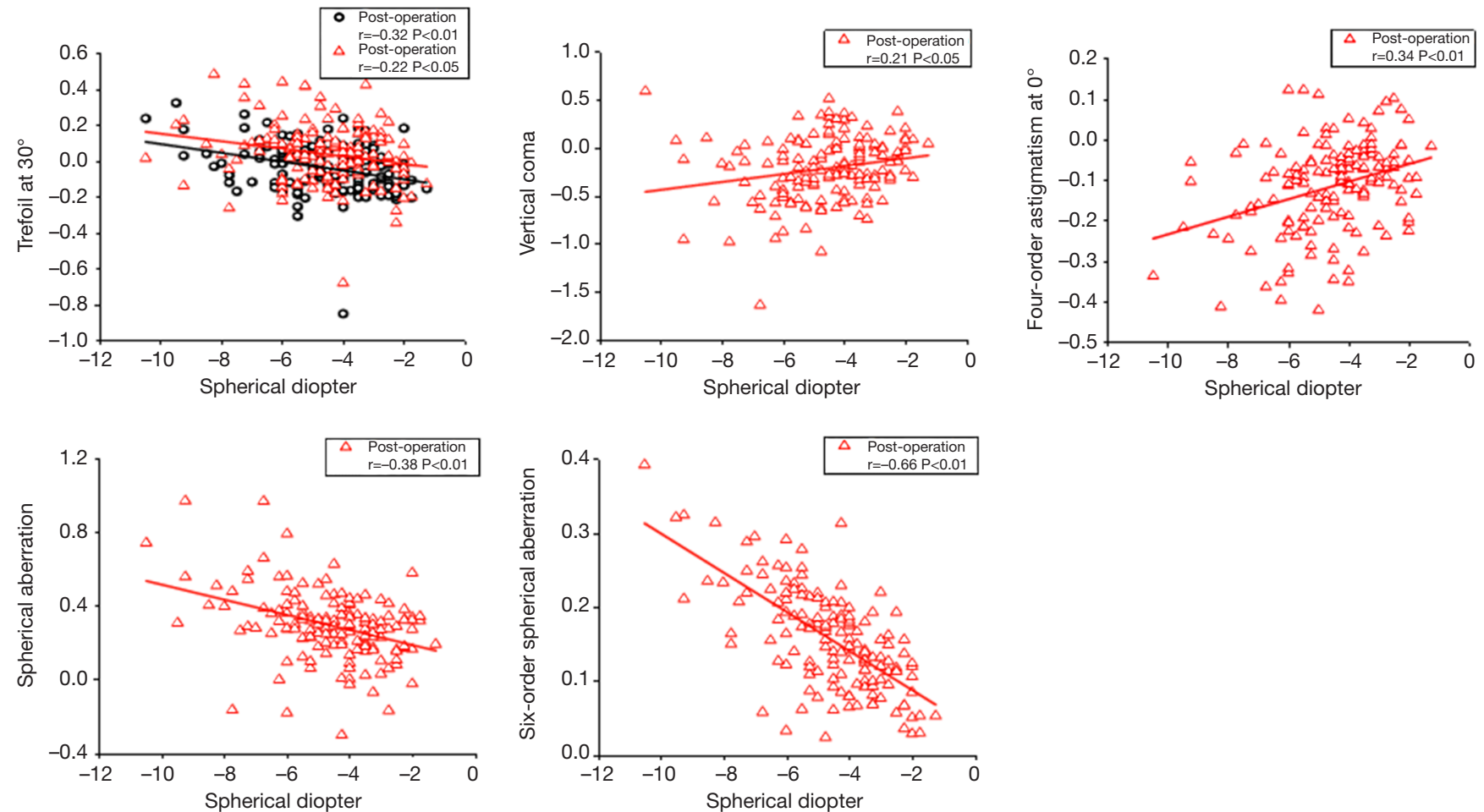

Figure 1 Relationship between spherical diopter and corneal high-order aberrations before and after surgery.
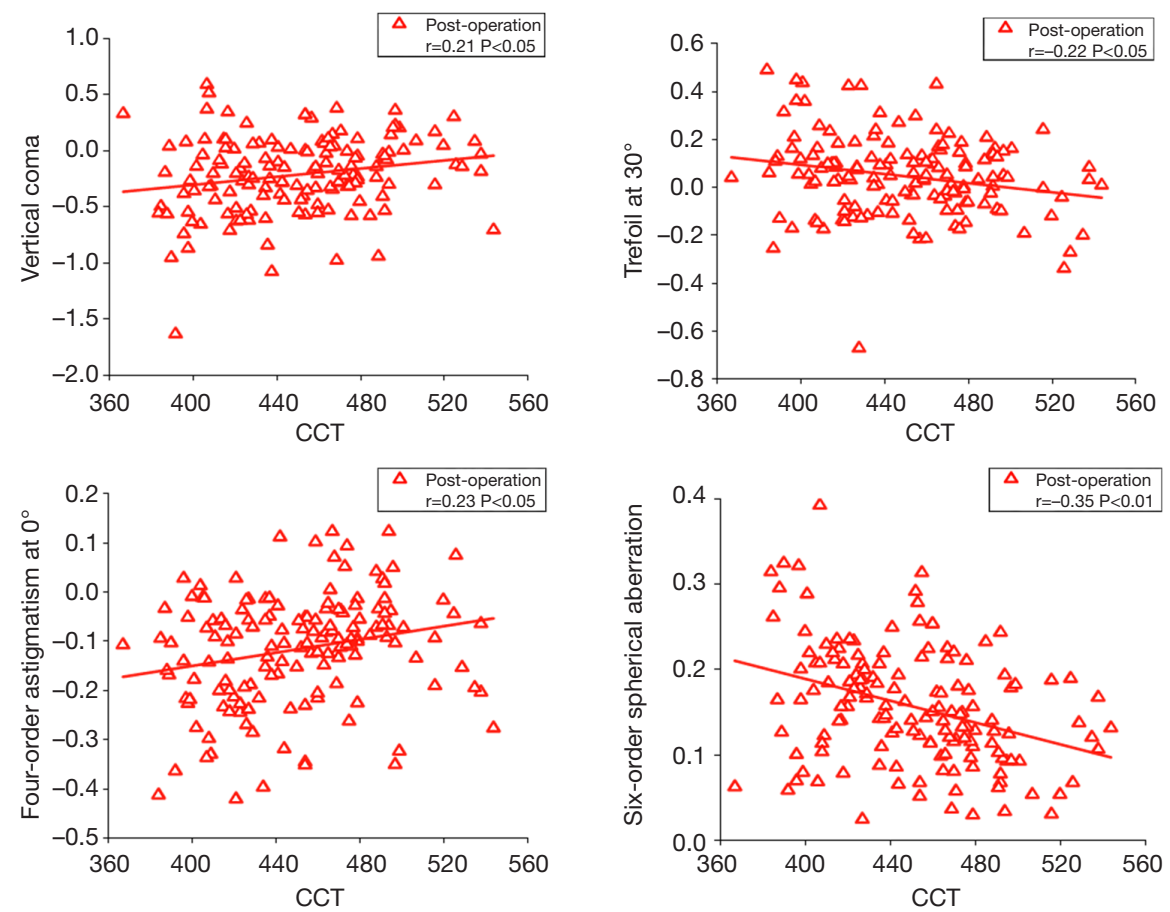

Figure 2 Relationship between central corneal thickness (CCT) and corneal high-order aberrations after surgery. 

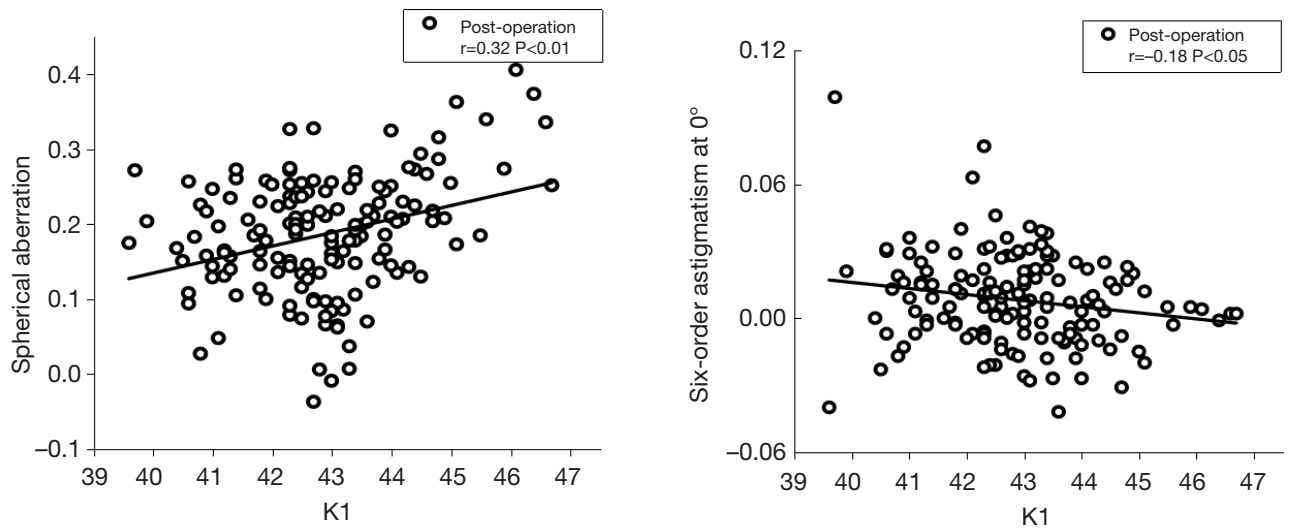

Figure 3 Relationship between the horizontal refractive power of the cornea (K1) and corneal high-order aberrations before surgery.
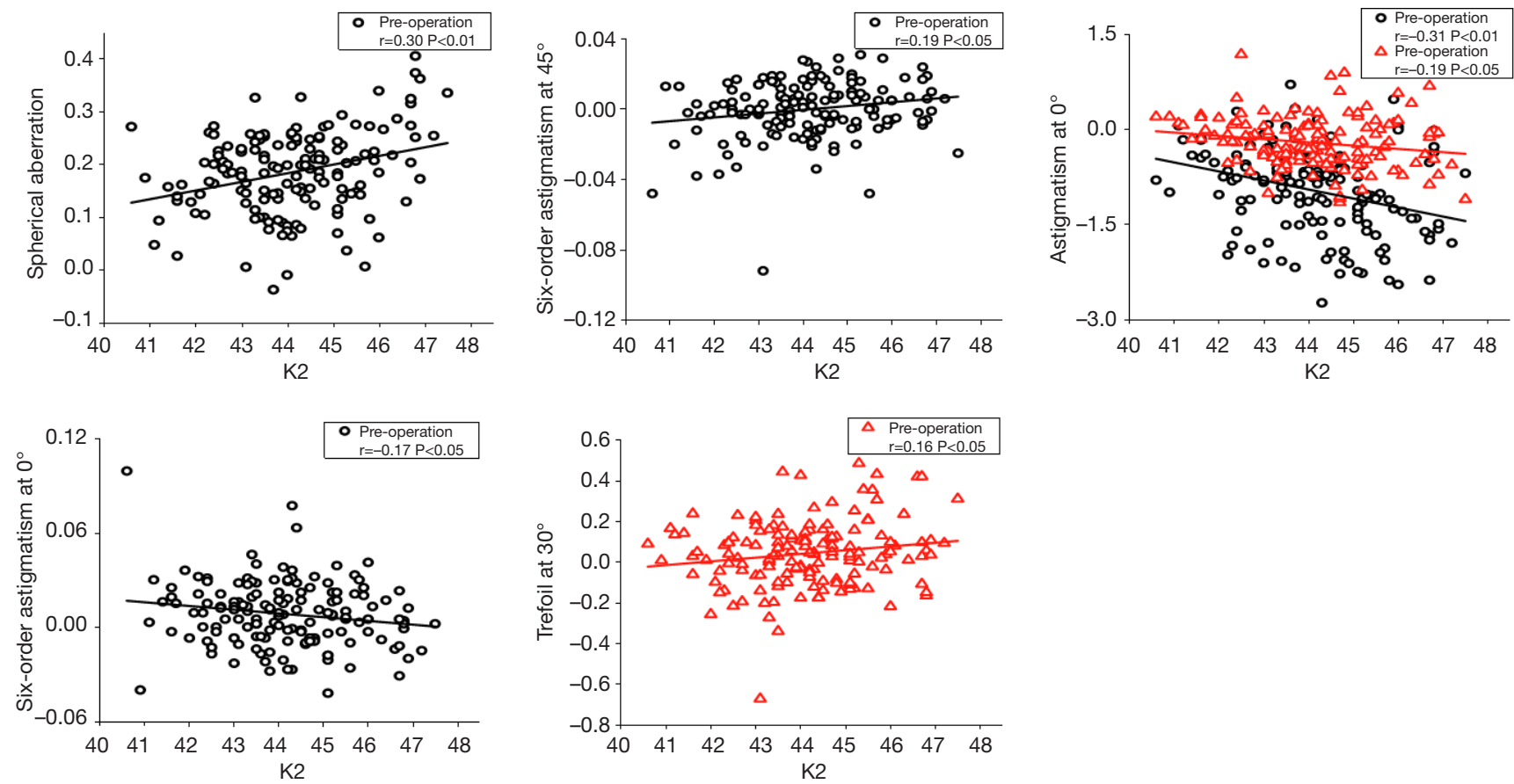

Figure 4 Relationship between the vertical refractive power of the cornea (K2) and corneal high-order aberrations before and after surgery.

Q were not correlated with corneal HOAs after surgery. $\mathrm{K} 2$ was positively correlated positively with trefoil at $30^{\circ}$ $(\mathrm{r}=0.16, \mathrm{P}<0.05$; Figure 4$)$, and negatively correlated with astigmatism at $0^{\circ}(\mathrm{r}=-0.19, \mathrm{P}<0.05$; Figure 4$)$. $\mathrm{Rm}$ was positively correlated with astigmatism at $0^{\circ}(\mathrm{r}=0.18, \mathrm{P}<0.05$; Figure 6).

\section{Discussion}

In FS-LASIK, HOA, spherical aberration, and vertical coma have significantly increased postoperatively (17). Therefore, it is necessary to explore the factors related to corneal aberration. The present study investigated the factors related to HOAs of the cornea before and after FSLASIK using Pentacam, and the results showed that corneal parameters K1, K2, Q, Rm, and CCT were correlated with preoperative and postoperative corneal HOAs. K1, K2, Q, and $\mathrm{Rm}$ were significantly correlated with corneal HOAs before surgery, whereas spherical diopter and CCT were significantly correlated with corneal HOAs after surgery. 

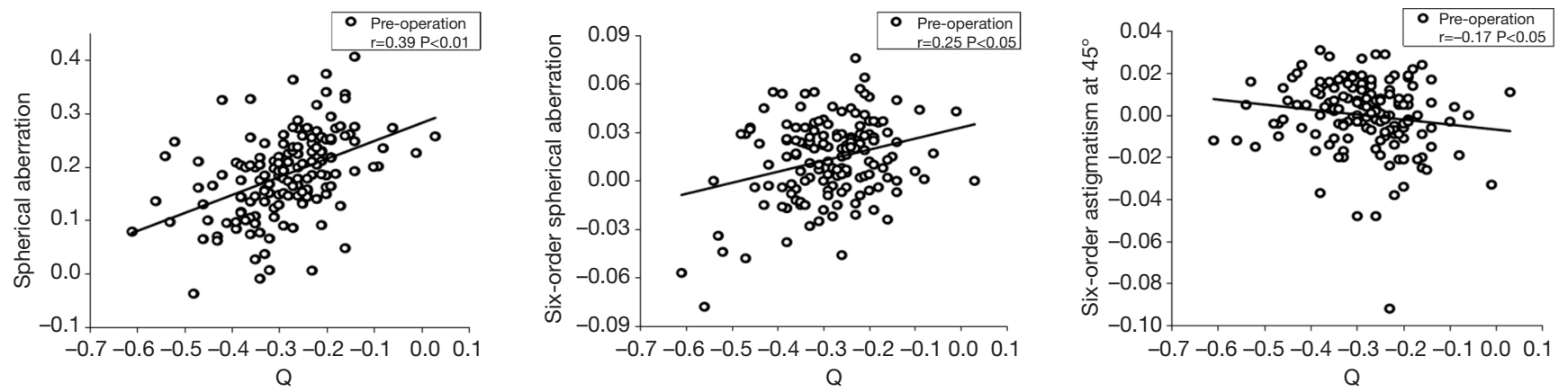

Figure 5 Relationship between the aspheric characteristics of the cornea (Q) and corneal high-order aberrations before surgery.
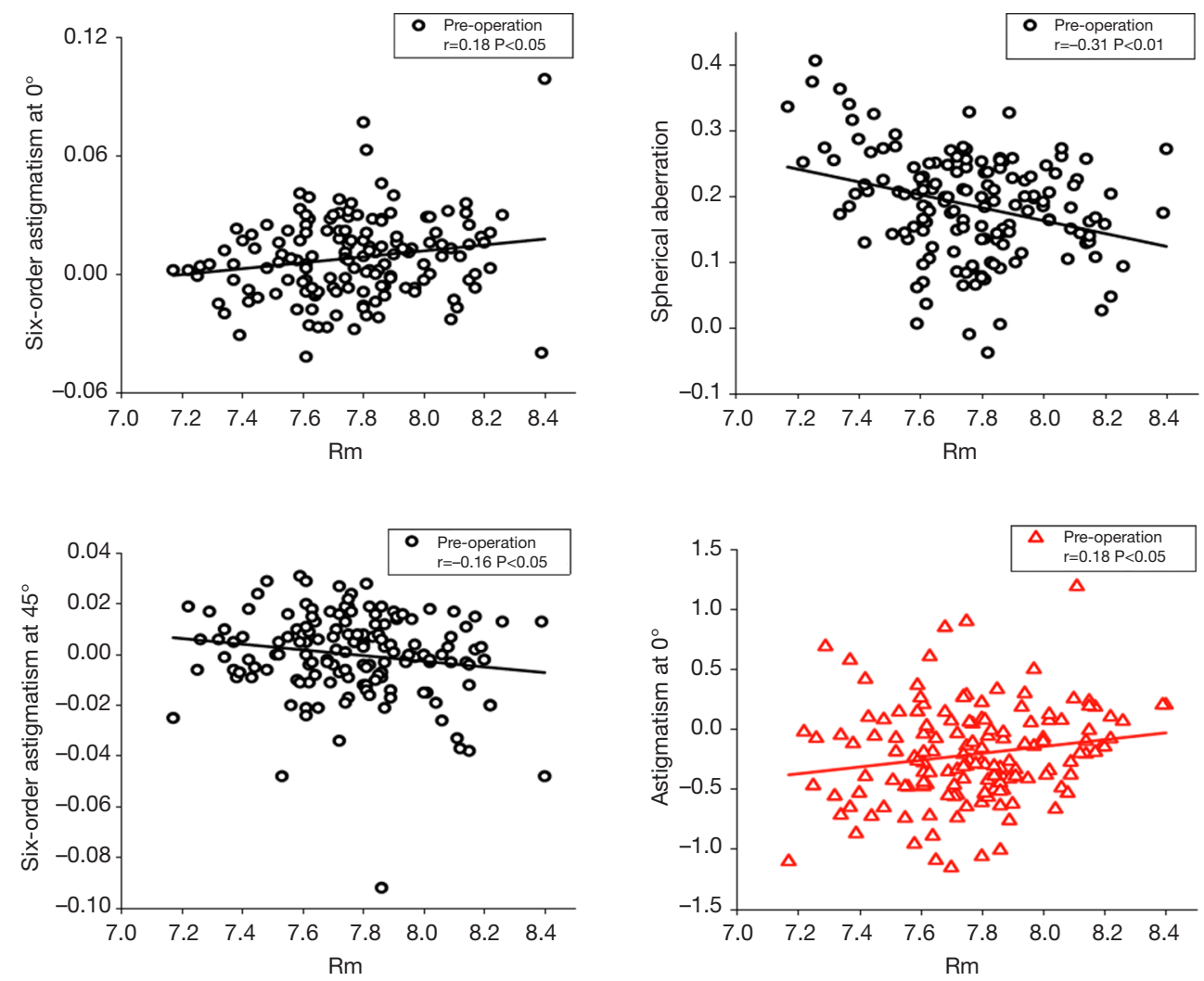

Figure 6 Relationship between the mean radius of the curvature of the cornea (Rm) and corneal high-order aberrations before and after surgery.

K1 was only correlated with preoperative corneal HOAs, especially spherical aberration, but not with postoperative corneal HOAs. K2 was mainly associated with spherical aberration and astigmatism before surgery, and was associated with trefoil at $30^{\circ}$ after surgery. Zhang et al. found that corneal spherical aberrations were correlated with $\mathrm{K} 1$ and $\mathrm{K} 2$ in myopia (18), which is consistent with our results. $\mathrm{Rm}$ is the mean radius of the curvature of the cornea. A weak negative correlation was found between corneal curvature radius and corneal spherical aberration in a Tanzanian population (19), which was consistent with our study in Chinese people. In our study, Rm was correlated with spherical aberration and astigmatism before surgery and with trefoil at $30^{\circ}$ after surgery. 
The corneal Q-value could reflect the change in corneal power from the center to the periphery, which represents the aspheric properties of the cornea. In the present study, Q was related to spherical aberration and astigmatism before surgery, but was not related to corneal HOAs after surgery. Jiménez et al. found that the change in corneal asphericity is related to visual quality after refractive surgery (20). Spherical aberration has been identified as a key contributor to the deterioration of image quality, night myopia, and photic complaints (21). In our study, K1, K2, Q, and $\mathrm{Rm}$ were associated with corneal spherical aberration before surgery, highlighting the crucial role of corneal curvature in visual quality. After surgery, CCT and spherical diopter were associated with spherical aberration, coma, trefoil, and astigmatism. Previous studies have shown that spherical aberration and coma have major effects on visual function $(15,22)$. Therefore, we conclude that CCT and spherical diopter are closely related to postoperative visual quality, which may help us to predict the postoperative visual quality of patients.

The mean HOA of patients complaining of complications was 2.26-fold higher than that of patients without complications (11). Preoperative corneal parameters and spherical diopter associated with FS-LASIK surgery may help us predict postoperative corneal aberrations, which can in turn help in deciding the surgical approach that can reduce postoperative corneal HOAs, and thereby improve visual quality. In our study, we analyzed the corneal aberrations up to the sixth order. Zernike terms up to the sixth order might provide an incomplete characterization of ocular aberrations; however, the contribution of each order to the overall HOAs decreased with increasing order, suggesting that higher orders contributed even less to the aberrations. To the best of our knowledge, no other studies published to date have evaluated the relationship among spherical diopter and corneal parameters with corneal HOAs. This is potentially important for FS-LASIK because it may be beneficial in predicting and improving the postoperative visual quality of patients.

This study has some limitations that should be noted. Firstly, patients were only followed up for 6 months after surgery. Furthermore, only one method of surgery was used, which does not provide a sufficient basis to demonstrate that other types of surgery, such as smallincision lenticule extraction and wavefront-guided laser in situ keratomileusis with iris registration, have the same effect. Further studies on other laser refractive surgery methods with larger sample sizes and longer follow-up periods are needed. Moreover, an increase in HOA after refractive surgery could degrade the quality of vision; hence, accurate analysis of the factors related to aberrations and the techniques to lower HOA is crucial to improving visual quality. At present, there is no surgical method that can effectively reduce the corneal HOAs, and different surgical methods may cause different HOAs $(23,24)$. Some surgical modalities, such as small-incision lenticule extraction and wavefront-guided laser in situ keratomileusis with iris registration, have shown advantages in reducing postoperative high order corneal aberrations, but some of HOAs are still relatively obvious $(24,25)$. In our study, we can only detect corneal HOAs by pentacam, there is no visual simulation device to simulate the visual field after the occurrence of HOA when explaining the risks and side effects before FS-LASIK. Therefore, future studies should aim to predict postoperative corneal HOAs and discover a surgical method that can reduce corneal HOAs after laser refractive surgery.

\section{Conclusions}

Our results expanded the present understanding of the factors associated with HOA of the cornea before and after FS-LASIK. We demonstrated that K1, K2, Q, Rm, and spherical diopter were related to corneal HOAs before surgery, whereas K2, spherical diopter, and CCT were related to corneal HOAs after surgery. Since an increase in HOAs after FS-LASIK is associated with lower visual quality, it is important to investigate potential solutions that will decrease the risk of corneal HOAs after FS-LASIK and thus improve visual quality.

\section{Acknowledgments}

Funding: The project was sponsored by grants from the National Natural Science Foundation of China (61975030) and the Department of Education of Guangdong Province (2020KTSCX130).

\section{Footnote}

Reporting Checklist: The authors have completed the STROBE reporting checklist. Available at http://dx.doi. org/10.21037/atm-21-2367

Data Sharing Statement: Available at http://dx.doi. org/10.21037/atm-21-2367 
Conflicts of Interest: All authors have completed the ICMJE uniform disclosure form (available at http://dx.doi. org/10.21037/atm-21-2367). The authors have no conflicts of interest to declare.

Etbical Statement: The authors are accountable for all aspects of the work in ensuring that questions related to the accuracy or integrity of any part of the work are appropriately investigated and resolved. The research protocol was approved by the Institutional Review Board of the First People's Hospital of Foshan (No. L-2018-3) and adhered to the tenets of the Declaration of Helsinki (as revised in 2013). All patients agreed to participate and signed an informed consent.

Open Access Statement: This is an Open Access article distributed in accordance with the Creative Commons Attribution-NonCommercial-NoDerivs 4.0 International License (CC BY-NC-ND 4.0), which permits the noncommercial replication and distribution of the article with the strict proviso that no changes or edits are made and the original work is properly cited (including links to both the formal publication through the relevant DOI and the license). See: https://creativecommons.org/licenses/by-nc-nd/4.0/.

\section{References}

1. Al-Zeraid FM, Osuagwu UL. Induced Higherorder aberrations after Laser In Situ Keratomileusis (LASIK) Performed with Wavefront-Guided IntraLase Femtosecond Laser in moderate to high Astigmatism. BMC Ophthalmol 2016;16:29.

2. Sáles CS, Manche EE. One-year outcomes from a prospective, randomized, eye-to-eye comparison of wavefront-guided and wavefront-optimized LASIK in myopes. Ophthalmology 2013;120:2396-402.

3. Arora R, Goel Y, Goyal JL, et al. Refractive outcome of wavefront guided laser in situ keratomileusis and wavefront guided photorefractive keratectomy in high preexisting higher order aberration. Cont Lens Anterior Eye 2015;38:127-33.

4. Lee JM, Lee DJ, Jung WJ, et al. Comparison between anterior corneal aberration and ocular aberration in laser refractive surgery. Korean J Ophthalmol 2008;22:164-8.

5. Ang RE, Chan WK, Wee TL, et al. Efficacy of an aspheric treatment algorithm in decreasing induced spherical aberration after laser in situ keratomileusis. J Cataract Refract Surg 2009;35:1348-57.
6. Baron WS, Munnerlyn C. Predicting visual performance following excimer photorefractive keratectomy. Refract Corneal Surg 1992;8:355-62.

7. Vongthongsri A, Phusitphoykai N, Naripthapan P. Comparison of wavefront-guided customized ablation vs. conventional ablation in laser in situ keratomileusis. J Refract Surg 2002;18:S332-5.

8. Seiler T, Reckmann W, Maloney RK. Effective spherical aberration of the cornea as a quantitative descriptor in corneal topography. J Cataract Refract Surg 1993;19:155-65.

9. Williams D, Yoon GY, Porter J, et al. Visual benefit of correcting higher order aberrations of the eye. J Refract Surg 2000;16:S554-9.

10. Oshika T, Klyce SD, Applegate RA, et al. Comparison of corneal wavefront aberrations after photorefractive keratectomy and laser in situ keratomileusis. Am J Ophthalmol 1999;127:1-7.

11. McCormick GJ, Porter J, Cox IG, MacRae S. Higherorder aberrations in eyes with irregular corneas after laser refractive surgery. Ophthalmology 2005;112:1699-709.

12. Kelly JE, Mihashi T, Howland HC. Compensation of corneal horizontal/vertical astigmatism, lateral coma, and spherical aberration by internal optics of the eye. J Vis 2004:4:262-71.

13. He JC, Gwiazda J, Thorn F, et al. Wavefront aberrations in accommodated eyes of emmetropes and myopes. Invest Ophthalmol Vis Sci 2003;44:U357-U357.

14. Artal P, Benito A, Tabernero J. The human eye is an example of robust optical design. J Vis 2006;6:1-7.

15. Wang J, Ren YL, Liang K, et al. Changes of corneal highorder aberrations after femtosecond laser-assisted in situ keratomileusis. Medicine (Baltimore) 2018;97:e0618.

16. Guirao A, Artal P. Corneal wave aberration from videokeratography: accuracy and limitations of the procedure. J Opt Soc Am A Opt Image Sci Vis 2000;17:955-65.

17. Zhang YL, Xu XH, Cao LJ, et al. Corneal curvature, asphericity, and aberrations after transepithelial photorefractive keratectomy and femtosecond laserassisted keratomileusis for myopia: A prospective comparative study. Indian J Ophthalmol 2020;68:2945-9.

18. Zhang X, Ma JH, Xi X, et al. Characteristics of corneal high-order aberrations in adolescents with mild to moderate myopia. BMC Ophthalmol 2020;20:465.

19. Asano H, Hiraoka T, Seki Y, et al. Distribution of corneal spherical aberration in a Tanzanian population. PLoS One 2019;14:e0222297. 
20. Jiménez JR, Alarcón A, Anera RG, et al. Q-optimized Algorithms: Theoretical Analysis of Factors Influencing Visual Quality After Myopic Corneal Refractive Surgery. J Refract Surg 2016;32:612-7.

21. Beiko GHH, Haigis W, Steinmueller A. Distribution of the corneal spherical aberration in a comprehensive ophthalmology practice, and can keratometry be predictive of the value of the corneal spherical aberration? J Cataract Refract Surg 2007;33:848-58.

22. Lee H, Yong Kang DS, Reinstein DZ, et al. Comparing corneal higher-order aberrations in corneal wavefrontguided transepithelial photorefractive keratectomy versus small-incision lenticule extraction. J Cataract Refract Surg 2018;44:725-33.

23. Gulmez M, Tekce A, Kamis U. Comparison of refractive outcomes and high-order aberrations after small incision

Cite this article as: Zeng J, Lan G, Zhu M, Sun K, Shi Q, Ma G, Liu Q. Factors associated with corneal high-order aberrations before and after femtosecond laser-assisted in situ keratomileusis. Ann Transl Med 2021;9(12):989. doi: 10.21037/ atm-21-2367 lenticule extraction and wavefront-guided femtosecondassisted laser in situ keratomileusis for correcting high myopia and myopic astigmatism. Int Ophthalmol 2020;40:3481-9.

24. Ye MJ, Liu CY, Liao RF et al. SMILE and WavefrontGuided LASIK Out-Compete Other Refractive Surgeries in Ameliorating the Induction of High-Order Aberrations in Anterior Corneal Surface. J Ophthalmol 2016;2016:8702162.

25. Chen X, Wang Y, Zhang J et al. Comparison of ocular higher-order aberrations after SMILE and Wavefrontguided Femtosecond LASIK for myopia. BMC Ophthalmol 2017;17:42.

(English Language Editor: A. Kassem) 